[Gordon, L. (1995). Is School Choice a Sustainable Policy for New Zealand? A Review of Recent Research Findings and a Look to the Future. New Zealand Annual Review of Education, 4, 9-24]

\section{Is School Choice a Sustainable Policy for New Zealand? A Review of Recent Research Findings and a Look to the Future}

\section{LIZ GORDON}

\section{Abstract:}

This chapter provides an overview of research on school choice and educational markets which has been undertaken in New Zealand over the past two years. The paper considers how choice should be conceptualized: as "voice" or "exit". It goes on to examine what is being chosen when parents and students look at schools, and notes that choices are severely constrained by a policy context which emphasises "exit". The next two parts of the paper examine the relationship between schools choice and the social and racial characteristics of schools, and notes the OECD's conclusion that school choice reflects a vertical social hierarchy rather than a horizontal diversity of real educational choices. Implications for both "loser" schools, and those at the top of the hierarchy are examined next, and there is a discussion of enrolment schemes. The paper concludes with a discussion of the implications of recent research for educational policy in this country, with an emphasis on policy sustainability

$\mathrm{M}$ uch has been written and said over the past few years about the "market" reforms of education that have taken place in New Zealand since 1989. The list of academic papers is long, most dealing with the conceptual and political implications of Tomorrow's Schools. Five years on, however, there is a small but growing literature which adds empirical evidence to prior insights. Cathy Wylie, in her most recent survey (1994), tests her findings against what she calls the "hopes and fears" expressed by policy-makers, academics and educators. Wylie's various studies have provided valuable baseline data on the changing views of those involved in the reform process: principals, boards of trustees, teachers and parents. Because her work is so broadlybased, it has provided a context in which other researchers have been able to undertake small-scale case studies of the effects of the reforms.

\section{Liz Gordon}

Empirical research is not superior to the kind of conceptual work which underpinned the earlier analysis of educational reforms. It has a specific purpose, however, in allowing us to make judgements about the actual effects of policies, and to test competing predictions based on conceptual work. Ball (1990) suggests that the British Education Reform Act constituted a "policy without pedigree"; a completely new form of education policy. The same may be said of Tomorrow's Schools. The research examined in this chapter provides a series of answers to crucial policy questions: Does the policy work? What work does the policy do? How does the policy match up with what was claimed for it? Although these are, in themselves, simple questions, they do not solve the crucial ideological differences that accompanied earlier conceptual analyses ideology cannot be "solved by the facts". What these questions can do is shift the ideological struggle to new terrain, forcing political responses to the failure of policy.

An analysis of New Zealand policies since 1989, and their effects, is made more complex by what Stephen Ball (1990:3) calls "discontinuities, compromises, omissions and exceptions" in the policy process. Two separate ideological rationales governed the inception of Tomorrow's Schools, and both still echo in and through the policy process (Wilson, 1991). There are a number of ways of treating this situation. In the Smithfield project, for example, the 1991 policy of balloting is specifically compared with that of enrolment schemes, which were in operation from 1992 onwards (Lauder et al., 1994). In my own research (Gordon, 1993; Gordon, Boyask and Pearce, 1994; Gordon, 1994), we have tended to look at the overall, cumulative effects of these, often contradictory, policies.

The first aim of this review is to examine what we know about the effects of those policies under Tomorrow's Schools that relate to school choice and markets. It is my belief, and the research done at the University of Canterbury backs this up, that the effects of policies of choice reach much further than their direct and immediate effects on schools. The ideological, political, and economic effects of school choice are deeply embedded in the social context in which the policy operates. The second purpose is to examine whether the current set of policies relating to choice and markets is sustainable into the future.

A policy can be considered to be sustainable when the mechanisms it creates perpetuate themselves in such a way as to maintain or enhance the goals of the policy. In other words, the way the policy works in itself maintains or enhances the goals of the policy. If a policy of parental 
choice of schools is being pursued, then we can expect that the mechanisms that are put in place will maintain or enhance the actual choices that are able to be made.

\section{Voice or Exit: Competing Approaches to Choice}

The concept of school choice was a central feature of Tomorrow's Schools. However, two competing versions of choice were evident in the early reforms. The first, characterised by "voice", emphasised the right of parents and communities to have a say in the education of their children. In the Picot Report, "voice" was to be exercised at the school level and also through Community Education Forums (Picot, 1988: 44). The second version emphasised the right of "exit", primarily of parents to make choices between state schools. Dale and Ozga (1993:76) note:

... exit and voice represent alternative forms of responses to dissatisfaction or discontent with organisations of which people are members or which exercise some influence or control over their lives.... Exit is an individualistic, economic response, while voice is a participatory, political response.

In the first two years of Tomorrow's Schools the emphasis was on "voice" rather than "exit", although inadequate avenues existed for the expression of that voice. Since 1991, however, the right to choose has been formally identified in New Zealand as the right of "exit"; choosing has become synonymous with choosing the "best" school for one's children. It is the patterns of exit (and entry) that underpin the various trends here. Had Tomorrow's Schools emphasised (and rewarded) "voice" within neighbourhood schools, rather than exit from them, the patterns described here would have been markedly different.

\section{What is Being Chosen?}

The emphasis on "exit" rather than "voice" forces schools into a competitive relationship with one another. Essentially, the goal for schools is to maximise, or optimise (the two are usually synonymous, although they may not be) the number of students that attend. Underpinning this relationship is the system of government funding for schools which, in the post-reform period, is based on per capita school attendance. Schools which lose pupils receive reduced government funding and will also, over time, lose teachers. These factors have caused the development of what has been called an education market. Wylie (1994:106) has documented the broad effects of competition on relationships between schools. 37 percent of school principals in her survey stated that the actions of other local schools had affected their school's roll. A number cited changes in ethnic and socio-economic composition of the schools as a result of market competition. The biggest effect of this was a change in the schools' self-promotion activities. Wylie also notes:

Deterioration in the school's relationship with other local schools since the start of the Tomorrow's Schools reforms was more likely to be reported by principals at those schools whose socio-economic composition had altered, and those whose own school promotion

had been affected by other local schools' actions (Wylie, 1994:106).

Wylie's survey demonstrates that the education market has impinged markedly on the work of schools. However, it is the Smithfield study (Lauder et al., 1994) which shows the full extent of these effects. The first report of the Smithfield project documents a particular secondary school education market in an urban area. Four schools are represented in the study, and data is gleaned predominantly from school principals. The first significant finding is that the abolition of zoning has had significant effects on both the rolls and social composition of the four schools. However, these effects have magnified and reinforced existing trends, rather than creating new ones. For example, Kauri College, which "has been at the 'bottom of the heap' for a long time according to local principals" (ibid: 44), has almost halved its third form intake since 1990. On the other hand, Manuka College, "at the top of the local hierarchy" (ibid: 50), was set to grow rapidly. This school introduced an enrolment scheme (see discussion of enrolment schemes below) and capped its roll at 1050, ironically assisting other schools in the area to survive at the same time as enhancing the popularity of the school (ibid: 51).

The process whereby existing hierarchies are enhanced by the imposition of school choice was also highlighted by my own study of ten schools in Christchurch (Gordon, 1993). The schools were picked very much at random, and there was a universal relationship between the wealth of the area in which a school was located and the direction of movement of the school's rolls. This study identified the status of the school neighbourhood as a powerful factor influencing school choice. A follow-up study (Ainsworth et al., 1993) undertook a survey of school roll movements in all Christchurch schools over five years, and identified that the patterns noted by Lauder et al. and myself were clearly evident throughout the city, although not universal. While all schools in wealthy areas had increases in their rolls, some schools in poorer areas also had increases, probably at the expense of other similar schools. 


\section{Why are Chosen Schools Chosen?}

The relationship between socio-economic factors and changes to school rolls has to be explained in terms of the actual choices made by parents. To date, only one complete study has been undertaken on parental choice in New Zealand. Mike Fowler's (1993) study focuses on four schools in south and west Christchurch. He interviewed parents of children in their final year of full primary or intermediate schooling about their choices of secondary school. The crucial finding of Fowler's study is that decisions tend to be made by parents on criteria that are primarily social:

In choosing Lincoln over Hillmorton, 25 percent of the comments made concerned Halswell parents' preferences for a "pleasant rural environment" and "fewer social problems" at Lincoln as against Hillmorton, which they saw as being in a "low socio-economic area" or in an "undesirable town environment" with "undesirable young people living in the area". In choosing Lincoln or Riccarton over Hornby, 28 percent of the comments made by Branston parents also focused on Homby's "low socio-economic area", "undesirable young people", "drugs" and "racial groups" and a "rough element". A socioeconomic and social motive underpinned parents' reasons for considering schools which were further away (Fowler, 1993: 108, author's emphasis).

In other words, the patterns of school choice identified in the previous section are directly related to the class and ethnic character of the area in which schools are located; the class effects noted above are not adventitious, but are central to education markets. These findings are similar to those of Waslander and Thrupp (1993), who, in an analysis of some of the Smithfield data, state:

In general terms our study has found that the concerns of market critics are justified. The choice to travel out of what was defined as the local zone prior to 1991 is more likely to be made by those from the upper end of each social stratum, irrespective of the ethnic background of the parents. Socio-economic segregation between schools has been exacerbated more than would be predicted simply on the basis of residential segregation (Waslander and Thrupp, 1993:31).

Evidently, not all parents are empowered to make choices to move their children from unpopular schools. Some, as Fowler notes, stay in such schools because of a commitment to the concept of community schooling (1993:108). It is those who seek social improvement who tend to send their children further afield. As one parent comments in Fowler's study, she wished to "avoid my children mixing with others who haven't been brought up the same as mine" (1993:109). Fowler also points out that those poorer schools which advertise themselves as being part of the community may be giving entirely the wrong message to attract those groups who precisely wish to escape their local community Given the growth in the number of enrolment schemes in popular schools, a further factor, that it is now schools, not parents, who often do the choosing, also needs to be taken into account (see below).

\section{Characteristics of School Populations}

The reasons that parents give in Fowler's study for sending their children to certain schools reflects, in some senses, real differences between school populations. My 1993 study highlighted a number of key differences between the makeup of school populations in different socio-economic areas. Central to these differences was the relative transience of the population in poorer schools, which is clearly demonstrated in the following case study extract:

A large proportion of the School's population is relatively transient, hence the roll fluctuates a great deal and less than half of all pupils enrolled at the present time commenced their schooling at Bayview School. An additional factor influencing the transient nature of the School's population is the temporary enrolment of the children of women staying at refuges in the School's zone (Gordon, 1993:5).

In poor areas, large sections (often more than half) of the families survive on benefits, live in single parent families and experience various effects of poverty, such as inadequate clothing or food, which impinge on school life. In other words, the transience of the population is matched by an insecurity of lifestyle. The combination of those factors makes learning in school harder.

This contrasts with schools in wealthier areas, where a large proportion of young people remain at one primary school until they enter intermediate or secondary school. These young people are more likely to have a secure home life conducive to good learning, parents who have experienced success in education, and adequate clothing and food.

If, as Waslander and Thrupp argue, families at the top of each class group are exerting choice to move to more socially-advantaged schools, then the differences already evident between school populations will continue to increase. As Hirsch (1994:15) notes: 
even a small minority of "active choosers" can have a considerable financial impact (on schools).... Of greater concern is the danger that these choosers will be members of privileged groups who have access to information and transport, leaving the less privileged in schools that deteriorate for lack of resources.

An implication of this trend is that within schools, there will be increasingly homogenous class groupings, while between schools differences will be enhanced. Also, because the trend of school choosers is "upward" in class terms, those schools at the "top" of the hierarchy will experience increased pressure in demand for places, with the inevitable effect that they will introduce enrolment schemes to limit entry.

In New Zealand, class hierarchies are cut across by hierarchies of ethnicity. It is difficult, if not impossible, to separate the effects of the two when considering school choice. The Smithfield project did, however, note some distinct ethnic patterns of school choice in their case study of one market. After Tomorrow's Schools, the small proportion of Pakeha students were the first to leave Kauri College, followed later by Pacific Island students and the Maori students. Many of these students went to the next nearest school, Totara College, but a significant number of Maori students entered Rimu College, which was "developing an image as a bicultural school" (Lauder et al., 1994:44). Most of the students from Kauri College were effectively barred from entry to the high-status Manuka College, because this school implemented an enrolment scheme based on residential criteria at an early stage. Because patterns of residence are themselves linked closely to ethnicity, Maori and Pacific Island students tend to be maintained in schools at the lower end of the market hierarchy.

\section{The Spiral of Decline and What Schools Can Do}

Both the Christchurch studies (Gordon, 1993; Gordon et al., 1994) and the Smithfield project identified a "spiral of decline" associated with the trends noted above. The formula for this spiral of decline is as follows: schools at the bottom of the local market tend to lose pupils to neighbouring schools. These pupils tend to be those of the highest class groupings in the school (Waslander and Thrupp, 1993; Lauder et al., 1994:45), concentrating the social difficulties of those who remain. As a result of the loss of students, funding is reduced, although the costs of running the schools barely change (Gordon, 1993). Teaching positions are lost, and the number of classes taught and the diversity of subjects decline as a result (Lauder et al., 1994). As social disadvantage becomes concentrated in schools, it becomes increasingly difficult to raise funds through school fees and community fund-raising, while the costs of social disadvantage are increased. These factors combine to make a market recovery extremely unlikely.

Gordon et al. (1994) note that this spiral of decline has particular effects at the level of school governance. As boards of trustees in poorer schools tend to have fewer qualifications than those in wealthy schools, the decline in roll numbers and associated effects may easily be blamed on poor governance. This leads to a form of over-compensation whereby boards respond promptly to all demands from central agencies, whereas schools in wealthier areas may, and do, jealously guard their autonomy from central requirements. Further, the process of decline causes enormous insecurity among poor schools, as the threat of decreasing resources prevents planning for the future.

If the decline itself is caused by the social choices that parents make about the kind of children who attend a particular school, then there is little that schools can do to respond. A new principal may, if the previous one was perceived as less than competent, temporarily halt or reverse the trend of falling rolls. In my 1993 study (Gordon, 1993), I noted that those schools, mainly secondary that span both working class and middle class areas may be successful in attracting more students, but that, in terms of market success, it is crucial that these are the "right" (i.e., middle class) students (Lauder et al. make a similar point). In large working class areas such as South Auckland, Porirua or eastern Christchurch, schools may be able to improve their position at the expense of other similar schools.

The market is driven by image, not necessarily by what a school can objectively measure. Cathy Wylie's (1994) survey makes the point that few schools have responded to market pressures by changing their systems of curriculum or assessment; the most common response is to engage in advertising and other forms of promotion. This point is also made in the OECD's (1994) study of choice in six countries. Noting that it is notoriously difficult, even for academic researchers, to assess the academic impact of a school, the OECD says that "the atmosphere or ethos of the school seems to be at least as important" as are "situational" factors such as location (1994:25).

Hirsch (1994) states that while schools can alter the atmosphere and academic achievement factors, situational factors cannot easily be changed. It is my view that the New Zealand research, especially Fowler's study (1993), points to situational factors as being the biggest influence on school choice. This is probably because those who are 
choosing tend to be upwardly aspirant families. This requires further research; it is a hypothesis that the Smithfield project should, in future years, be able to answer.

\section{Enrolment Schemes - An Irresistible Bargain}

Increasing numbers of schools are being forced to introduce enrolment schemes to cap escalating rolls. As at December 1994, 321 schools had introduced enrolment schemes, which is 12 percent of total schools, but constitutes a much higher proportion of secondary and of urban schools. The majority of these schools base their schemes on a modified system of zoning, taking people first who live in specified areas close to the schools. As these tend to be in middle class areas, for reasons discussed above, such zones tend not to broaden the class mix of the school. Only a few schools use a system of balloting, which Lauder et al.'s (1994) data suggest is the most equitable form of selection in socio-economic terms.

Enrolment schemes cut across and directly limit parental choice. Under enrolment schemes parents do not choose schools; schools choose students according to rules set out by the school. These rules are limited only by human rights legislation on discrimination. Two studies (Lauder et al., 1994 and Gordon, 1994) have examined the role of enrolment schemes. In Lauder et al.'s study, the local secondary school at the top of the hierarchy negotiated an early (1992) enrolment scheme with the Ministry of Education. The aim was to cap the school roll at a figure far below original Ministry estimates of the school's capacity Two reasons were given for this by the school's principal. The first was that, in his experience, smaller schools were better than larger schools. Secondly, the principal noted:

We were suddenly in the position of having absolutely no control over who came here and people came to the school with a range of educational problems for which we had no solutions because we had no special or discretionary staffing to deal with them (Principal of Manuka College, quoted in Lauder et al., 1994:50).

Under the new enrolment scheme, the smallness of the school could be guaranteed. The principal apparently believed that the enrolment scheme would also protect the school against those educational problems he discusses, the implication being that these are imported from outside of the immediate area of the school (and that they should be dealt with by other schools).

Lauder et al. note that:

since imposing a zone, (Manuka College's) exclusivity has intensified and its reputation consolidated. It has reinforced its dominant position in the local hierarchy and has become more competitive with the high SES schools further afield (1994:51).

This is a finding also of Gordon et al.'s (1994) study The imposition of an enrolment scheme reinforces the success of a school. Exclusivity apparently equates with desirability in education markets. Schools with enrolment schemes are also in the position of being able to guarantee their population in subsequent years, which aids in resource planning.

In this study, two schools put enrolment schemes in place during the period in which the research was undertaken. Oakdale Primary School, located in one of the most desirable residential areas in Christchurch, was forced by overcrowding to implement an enrolment scheme. Unable to grow in size because of limited grounds, the school was subject both to high demand from out-of-zone children and the effects of new in-fill housing. The school's enrolment scheme stated that siblings of children already at the school would have first priority, followed by those "who would not be able, reasonably conveniently, to attend some other state school" (Gordon et al., 1994:62). This formula avoided the necessity for a geographical zone to be specified, but also put into the hands of the school the power to make judgements about what constitutes "convenience". Longford College introduced a traditional geographical zone, but specified a set of criteria by which out-of-zone children would be selected. The specific zone which was put in place for 1994 was significantly smaller than in previous years. It was not clear from the research study whether Longford's success was caused by a growth in the middle-class population of the school, but even in the first year of the scheme the school was forced to turn a number of students away.

Enrolment schemes act as a major influence on educational markets. They both attract students, and also ensure that other schools in the vicinity do not "fail" completely, even if many of the students at these schools are "rejects" from more popular schools. They also en hance social hierarchies, given that schools with enrolment schemes tend to be located in wealthier areas (there are, at present, no figures available to confirm this). Because of the class pattern of ethnic mix in New Zealand, they also influence ethnic balance within a school. Finally, enrolment schemes have a tendency to reinforce social exclusivity, even if none of the schools studied thus far have taken the potential route described by Hirsch:

There is nothing to stop the school board of an oversubscribed New Zealand school from drawing its catchment area in a shape that includes just those socially privileged streets from which it would like 
to draw its clientele - knowing that this will consolidate its market advantage (1994:23).

In a number of senses, then, schools with enrolment schemes, whether wittingly or unwittingly, control the market in their immediate (and sometimes extended) geographical area. This tendency Hirsch (1994) refers to as being a "negative externality" of education markets.

\section{Social Hierarchies or Horizontal Diversity?}

In the absence of either a price mechanism or an obvious system for readily expanding supply to meet demand, markets will only clear if an obvious hierarchy of schools ranked by desirability can be avoided. That is to say, many people's choices will be frustrated unless people choose in different ways from each other (Hirsch, 1994:24).

The evidence from the research studies on school choice in New Zealand shows that choice of school is strongly linked to the social status, rather than the educational resources, of a school. This situation is strongly selfreinforcing. Schools with a mainly middle-class and Pakeha (or, increasingly, Asian) population, tend to achieve better on national examinations because of the high level of educational "readiness" and motivation of the pupils, and relatively low levels of social problems that impinge on educational processes.

The policy of school choice, and especially the encouragement for parents to practice exit strategies, has directly enhanced pre-existing patterns of school attendance because, with the exception of Kura Kaupapa Maori, there has been no attempt to provide any form of market diversification other than social hierarchies. In other words, there is a dearth of real educational choices within state schools, leaving certain groups of people to "choose up" rather than to "choose across". The Picot Report argued that, through the charter and local management, schools would take on and cater to local needs (1988:45). Only if schools failed to respond to the community "voice" would there be the likelihood of "exit", especially through groups of parents combining to begin a new school (a similar strategy to that employed in Sweden). Thus "voice" was to provide the main mechanism for horizontal diversity within schools. The shift to "exit", however, had the opposing effect, emphasising the social hierarchies of schooling. This is why "situational" factors have taken on such importance in New Zealand's education market.

It may be argued, however, that there is nothing to stop schools working to develop niche markets, especially as they are losing students and need to attract others. However, Hirsch points out that this is a risky strategy:

Where schools are not given particular specialised missions, there can be a strong tendency for them all to try to market the same standardised product of a "sound" education, especially where attempts to define a common curriculum from the centre are strong... This tendency to aim in a competitive market to sell a "staple" product rather than search for niche markets is not surprising given the cost to any one school of losing pupils within its local "catchment" area (Hirsch 1994:21).

The policy of open enrolment was enacted in the Education Amendment Act of 1991. From 1992 on, according to Lauder et al. (1994), the effects of this can be seen in the increasing social polarization of school enrolments. Every new enrolment scheme which selects by residential criteria reduces the possibility of social diversity within schools. As well, parents who live in the higher socio-economic areas of major centres may find their choices narrowed to a single school by the increase in enrolment schemes.

At the other end of the socio-economic spectrum, parents may find themselves able to choose between a number of schools, but these schools are available to be chosen simply because few others have chosen them, which constitutes a limited form of choice. Many schools in these areas may be saved in the future simply because there is a new population bulge starting to come through our schools. Demographic patterns will ensure that few urban schools will close, but will also put enormous pressures on schools, leading to a further expansion in the numbers with enrolment schemes.

A final point to make in this section is that choice is largely irrelevant in most schools in New Zealand, which are located in rural areas. Choice is an urban phenomenon. Except for the wealthy rural elite, who have always tended to send their children away to private schools, most rural families send their children to the closest school, and even this may be located many kilometres from home. In this situation, it is voice, not exit, which will provide for the educational needs of the community.

\section{Recommendations from the Research: Is Choice Policy Sustainable?}

The results of the comparative OECD study (1994) indicate that a pure market form is not likely to work in the education sector across all countries. The OECD makes the point that "policies to promote school choice can have a serious impact, sometimes undesired, on educational 
systems and on educational chances" (1994:49). However, this report states that some form of parental choice is probably necessary, and that "instruments are available to manage choice more effectively in line with desired educational and social outcomes". As the country with the purest "free market" approach to choice, New Zealand needs to heed this advice. While it is clear from Wylie's studies that schools and parents do not want to return to the confining central regulation of the past, the way forward is far from clear at this point. The perverse and unintended consequences of a socially-determined market for schooling needs to be addressed urgently at the level of policy. Even political parties which advocate a straight privatization of the education system, with a voucher "safety net" (Douglas, 1993), do so in the hope of improving, not narrowing, educational opportunities for all groups in this country. What is needed is a policy approach that combines the older social democratic goal of educational comparability across class and ethnic boundaries, with real choices for families.

Most of the "realised fears" addressed in Wylie's (1994:139) analysis relate to the effects of school choice and market competition. She notes that "resource disparities between schools have increased", that "schools least well resourced are those serving disadvantaged groups", that "increased competition between schools is apparent even at the primary level" and that "parents are making more financial contributions to their child's school" (ibid). She concludes that school-based management:

...cannot, of and by itself improve the educational provision for students from disadvantaged groups. Government leadership and improved renouncing overall is necessary if schools are to make any more headway on the most critical challenge facing New Zealand education (1994:140).

The recommendations of the OECD report address the broader considerations that any educational context should take into account in expanding school choice. First, government should intervene to ensure choices for groups who are "educationally underserved". The report suggests added and varied information, school transport policies, and a form of quota system to counter a situation in which choice "systematically gives superior opportunities to children whose parents can afford to live near good schools" (1994:51). The report stops short of recommending financial compensation for those schools which are market losers, although this point is raised by Hirsch (1994).

Second, to avoid the pattern of vertical social choice, initiatives should be introduced at governmental level to diversify supply, "where a wide choice of educational options is seen as desirable" (OECD, 1994:51). The report states that "there is a greater chance that educational innovation will result under a diversified than a hierarchical system of choice, and therefore more likelihood that choice will lead to improvements in education" (ibid).

Third, the OECD recommends "measures to improve the supply of chosen options" (ibid). Two suggestions are made. The first is to help successful schools expand (but a barrier to this is that relative smallness is often, of itself, attractive; see Lauder et al., 1994). The second is to assist unpopular schools to replicate "the qualities sought by parents in successful" schools (OECD, 1994: 51). The New Zealand research holds out little hope for this suggestion however, as social and situational factors play such a major role in determining choices, and these are generally beyond the control of the school.

Finally, the report calls for clear criteria to be instituted for selection of pupils by schools. This is an area of contention in New Zealand. The Smithfield project argues that evidence in their sample shows that schools are choosing on the basis of social criteria, although these cannot, of course, be separated from residential and achievement factors. Policy in this area needs to be examined, as schools are, in practice, less than accountable for their choices. As noted in the Canterbury studies (Gordon, 1993; Gordon et al., 1994), improving the middle class student population brings a number of market and resource advantages to schools. The danger is that both low socio-economic schools, and the populations they serve, will become increasingly residual to the system as a whole.

The Smithfield study makes three specific recommendations (Lauder et al., 1994:65):

- $\quad$ every child should have the right to go to their local school;

- $\quad$ over-subscribed schools should use a system of balloting to select pupils; any other approach enhances social selectivity; and

- the policy pattern of exit is inappropriate for working class schools, and funding should be provided to compensate for this.

One problem that remains is that there are no clear mechanisms for achieving policy change along the lines suggested by recent research. The new structures of education do not provide for clear processes of policy consultation, and the failure of the multi-representative Schools Consultative Group in 1994 underlined this problem. A Ministerial Reference Group has been formed to address a number of aspects of 
policy, in particular the bulk funding of teacher salaries, but there is no indication as yet that this group will provide a broader review of the basis of existing policy. Schools, in particular, feel that their situation is not clearly understood by the central agencies and government.

The new funding formula announced in late 1994, Targeted Funding for Educational Achievement (TFEA), is a case in point. While, to an extent, this funding scheme is an acknowledgement of the effects of marketisation on schools in low socio-economic areas, the range of anomalies, apparent reduction in funding and lack of consultation epitomises the problems of policy change that exist in the schools sector at present. As the OECD report notes, Tomorrow's Schools has been widely perceived as a "cost-cutting exercise", designed to ensure that the "school system could be run more economically" (1994:8). Sustainable policy development requires processes of consultation and an assurance that decisions made will enhance the functioning of this sector. Thus before sustainable policies for education into the future can be achieved, the processes of policy-making in the education sector will need to be addressed.

\section{References}

Ainsworth, V. Tomorrow's Schools and Freedom of Choice - A Recipe for Disaster, Christchurch: Education Policy Research Unit, 1993.

Ball, S. Politics and Policy-Making in Education: Explorations in Policy Sociology, London: Routledge, 1990.

Ball, S. "Education markets, choice and social class: The market as a class strategy in the UK and USA", in British Journal of Sociology of Education 14/1, 1993:3-18.

Dale, R. and Ozga, J. "Two hemispheres - both new right? 1980s education reform in New Zealand and England and Wales", in Lingard, Knight and Porter (eds), Schooling Reform in Hard Times, London: Falmer Press, 1993.

Douglas, R. Unfinished Business, Auckland: Penguin Books, 1993.

Fowler, M. Factors Influencing Choice of Secondary School: A Case Study, Christchurch: University of Canterbury, 1993.

Gordon, L. A Study of Boards of Trustees in Canterbury Schools, Christchurch: Education Policy Research Unit, 1993.

Gordon, L. Boyask, D. and Pearce, D. Governing Schools: A Comparative Analysis, Christchurch: Education Policy Research Unit, 1994.
Gordon, L. "Rich and Poor Schools in Aotearoa/New Zealand", in New Zealand Journal of Educational Studies 29, 2, 1994.

Hirsch, D. "School choice and the search for an educational market", Unpublished manuscript, London: 1994.

Lauder, H. The Creation of Market Competition for Education in New Zealand: An Empirical Analysis of a New Zealand Secondary School market 19901993, Wellington: Ministry of Education, 1994.

Miliband, D. Markets, Politics and Education: Beyond the Education Reform Act, London: Institute for Public Policy Research, 1991.

Picot, B. et al. Taskforce to Review Educational Administration, Administering for Excellence (Picot Report), Wellington: Government Printer, 1988.

OECD. School: A Matter of Choice, Paris: 1994.

Waslander, S. and Thrupp, M. "Choice, Competition and Segregation: An empirical analysis of a secondary school market 1990-1993", Unpublished paper, 1993.

Wilson, K. "The Picot Report and the Legitimation of Education Policy", unpublished M Ed Admin, thesis, Massey University, 1991.

Wylie, C. Self-Managing Schools in New Zealand: The Fifth Year, Wellington: New Zealand Council for Educational Research, 1994.

\section{The author}

Liz Gordon is a Senior Lecturer at the University of Canterbury. Her research interests are in the areas of state theory, education policy and market reforms. 